\title{
PENDIDIKAN KARAKTER BERBASIS KEARIFAN LOKAL HUMA BETANG DALAM KEGIATAN PEMBELAJARAN ISMUBA KELAS X IPS DI SMA MUHAMMADIYAH KASONGAN
}

\section{CHARACTER EDUCATION BASED ON LOCAL HUMA BETANG LIFE IN LEARNING ACTIVITIES OF CLASS X IPS ISMUBA IN MUHAMMADIYAH KASONGAN}

Supriadi
Halpiani

Universitas Muhammadiyah

Palangkaraya

-Indonesia

email: adianstercool@yaho.com

\begin{abstract}
Abstrak
Ruang lingkup pendidikan, khususnya pendidikan karakter sangat luas, formal dan non formal baik di ranah keluarga, komunitas maupun lingkungan sekolah. Melalui sekolah proses menanamkan nilai-nilai karakter siswa akan diterapkan baik melalui kegiatan belajar mengajar, budaya sekolah, dan kegiatan pengembangan diri. Sebagai agen pembelajaran, guru dituntut tidak hanya menguasai materi pelajaran tetapi juga dituntut untuk merumuskan kegiatan pembelajaran agar memiliki kandungan nilai karakter di dalamnya, salah satunya adalah melalui pendidikan karakter berbasis kearifan lokal yang dapat diterapkan dalam kegiatan pembelajaran.

Penelitian ini difokuskan untuk mendeskripsikan: (I) Bagaimana pendidikan karakter berbasis huma betang kearifan lokal pada kegiatan pembelajaran kelas X ISMUBA di SMA Muhammadiyah Kasongan? (2) Bagaimana nilai karakter berdasarkan huma betang kearifan lokal dalam kegiatan pembelajaran ISMUBA kelas X IPS di SMA Muhammadiyah Kasongan?

Penelitian ini menggunakan pendekatan kualitatif, dan jenis penelitian deskriptif kualitatif, sedangkan subjek dalam penelitian ini adalah I (satu) guru ISMUBA, sedangkan informan dalam penelitian ini adalah Wakil Kepala Bagian Kurikulum dan Kepala Sekolah Tinggi Muhammadiyah Kasongan. Sekolah. Data yang dicari dalam penelitian ini dikumpulkan melalui teknik observasi langsung, wawancara dan dokumentasi yang divalidasi dengan Triangulasi, kemudian dianalisis melalui beberapa tahap yaitu pengumpulan data, reduksi data, penyajian data, penarikan kesimpulan dan verifikasi.
\end{abstract}

Kata kunci :

Pendidikan karakter,

Kearifan lokal,

Belajar ISMUBA.

Keywords:

Character education,

local wisdom,

ISMUBA learning.

\begin{abstract}
The scope of education, especially character education is very broad, formal and non formal both in the realm of family, community and school environment. Through schools the process of inculcating student character values will be applied both through teaching and learning activities, school culture, and self-development activities. As an agent of learning, teachers are required not only to master the subject matter but are also required to formulate learning activities to have a content of character values in them, one of them is through character education based on local wisdom that can be applied in learning activities.

This research is focused to describe: (I) How is character education based on huma betang local wisdom in class X ISMUBA learning activities at SMA Muhammadiyah Kasongan ?, (2) How is the value of character based on huma betang local wisdom in learning activities ISMUBA class X IPS in high school Muhammadiyah Kasongan?

This study uses a qualitative approach, and the type of descriptive qualitative research, while the subjects in this study are I (one) ISMUBA teacher, while the informants in this study are the Vice Principal of the curriculum section and the Principal of Muhammadiyah Kasongan High School. The data sought in this study was collected through direct observation techniques, interviews and documentation which were validated by Triangulation, then analyzed through several stages namely data collection, data reduction, data presentation, drawing conclusions and verification.
\end{abstract}

2020 The Authors. Published by Institute for Research and Community Services Universitas Muhammadiyah Palangkaraya. This is Open Access article under the CC-BY-SA License (http://creativecommons.org/licenses/bysa/4.0/).DOI: https://doi.org//0.33084/anterior.vl8i2.456.

\section{A. Pendahuluan}

Pendidikan memiliki posisi penting dalam kehidupan manusia. Mengingat pentingnya pendidikan bagi kehidupan manusia, maka Islam sebagai Agama yang rahmatan lil alamin, memberikan perhatian serius terhadap perkembangan pendidikan bagi kelangsungan hidup manusia. Dari pengertian di atas dapat dipahami pendidikan memiliki tujuan yang luhur. Keluhuran tujuan tersebut selayaknya tercermin dari potensi diri yang tergali, sikap dan tingkah laku yang bermoral dari peserta didik selaku subyek pendidikan. Pendidikan yang ada tidak hanya melahirkan seseorang yang ahli dalam bidang tertentu, akan tetapi bagaimana seseorang mampu membawa diri dalam lingkungan bermasyarakat, berbangsa dan bernegara sesuai 
dengan norma dan aturan yang berlaku. Selain itu Seiring dengan adanya perkembangan globalisasi yang sedang berlangsung saat ini, mau tidak mau berdampak bagi kehidupan masyarakat di Indonesia. Kemajuan teknologi informasi telah "membabat" habis batas-batas yang mengisolasi kehidupan manusia. Oleh karena itu, terbentuklah masyarakat yang terbuka (open society), dimana terjadi aliran bebas informasi, yakni manusia, perdagangan, serta berbagai bentuk-bentuk aktivitas kehidupan global lainnya yang dapat menyatukan manusia dari berbagai penjuru dunia. Oleh karena itu, masyarakat Indonesia mempunyai karakter tersendiri yang menjadi ciri khas dan berbeda dengan negara lain-nya, antara lain; I) keberagaman, 2) sikap saling pengertian, 3) toleransi 4) sanksi moral. Karakteristik ini diharapkan dapat mewarnai kehidupan sosial masyarakat Indonesia, sehingga dapat melahirkan masyarakat yang berpendidikan, berkarakter dan berbudaya.

Melalui dunia pendidikan inilah salah satu strategi dasar dari pembentukan karakter. Karakter bangsa yang kuat merupakan produk pendidikan yang baik. Hal ini tentu akan menghasilkan manusia yang baik pula. Sementara itu, jika melihat capaian dunia pendidikan sekarang, maka jelaslah bahwa karakter bangsa kita bukan merupakan produk pendidikan yang baik. Banyak peristiwa mengkhawatirkan terjadi di lingkungan pendidikan yang membuat dunia pendidikan semakin lumpuh. Ada siswa sekolah menjadi korban kekerasan. Sekolah yang seharusnya memberikan harapan dan optimisme, malah menjadikan anak didik trauma dan putus asa bahkan bunuh diri. Di tempat lain ada sekelompok pelajar yang tawuran, melakukan tindak asusila seperti aborsi. Rasa hormat siswa terhadap guru yang berkurang, serta hilangnya sopan santun dari para peserta didik terhadap orang lain baik guru, masyarakat dan lain sebagainya. Fenomena-fenomena tersebut menunjukan bahwa karakter dan moralitas bangsa kita tengah mengalami kemorosotan dan rusak. Untuk mengokohkan goncangan nilai karakter dan moral di atas perlunya upaya pembangunan karakter bangsa. Dalam kebijakan nasional pembangunan karakter bangsa tahun 2010-2025 ditegaskan bahwa karakter merupakan hasil keterpaduan dari empat bagian, yakni olah hati, olah pikir, olah raga, serta olah rasa dan karsa. Olah hati terkait dengan perasaan sikap dan keimanan, olah pikir berkenaan dengan proses nalar guna mencari dan menggunakan pengetahuan secara kritis, kreatif, dan inovatif, olah raga terkait dengan proses persepsi, kesiapan, peniruan, manipulasi, dan penciptaan aktivitas baru disertai sportivitas, serta olah rasa dan karsa berhubungan dengan kemauan dan kreativitas yang tercermin dalam kepedulian, pencitraan, dan penciptaan akan kebaruan. Oleh karena itu, diperlukan upaya dalam membentuk karakter bangsa, salah satunya dengan melalui institusi pendidikan yaitu sekolah.

Sekolah (pendidikan) merupakan salah satu tempat strategis dalam pembentukan karakter selain di keluarga dan masyarakat. Melalui sekolah proses penanaman nilai-nilai karakter siswa akan diaplikasikan baik melalui kegiatan belajar mengajar, budaya sekolah, maupun kegiatan pengembangan diri. Di dalam kegiatan belajar mengajar siswa dihadapkan pada materi yang kaya akan nilai pendidikan karakter, baik dari aktivitas belajar langsung (materi) maupun tidak langsung seperti tingkah laku guru yang memberikan nilai pendidikan karakter misalnya religius seperti mengajak siswa untuk membaca do'a sebelum memulai pembelajaran. Dalam pembelajaran (materi) langsung terdapat banyak sekali nilai-nilai pendidikan karakter yang bisa siswa ambil dan tugas guru menjabarkan 
nilai-nilai karakter yang dimaksud agar dapat diserap maksimal oleh siswa.

Sebagai agen pembelajaran, guru diharuskan bukan hanya sekedar menguasai materi pelajaran tapi juga dituntut untuk memformulasikan kegiatan pembelajaran agar memiliki muatan nilai-nilai karakter di dalamnya, Salah satunya melalui pendidikan karakter yang berlandaskan kearifan lokal yang dapat diaplikasikan dalam kegiatan pembelajaran. Kearifan lokal yang mulai pudar dan terkikis oleh perkembangan jaman dan tergeser oleh budaya asing yang masuk dengan begitu pesat mempengaruhi karakter suatu bangsa, sehingga membuat kearifan lokal yang berkarakter di daerah tersebut perlahan ditinggalkan dan mungkin saja hilang nantinya. Melalui proses pembelajaran yang berkearifan lokal diharapkan dapat mengangkat kembali nilai-nilai budaya yang mulai tergeser oleh perkembangan zaman dan pengaruh budaya asing.

\section{B. Deskripsi Teoritik}

\section{Urgensi pendidikan karakter}

Menurut Kamus Besar Bahasa Indonesia, karakter merupakan sifat-sifat kejiwaan, akhlak atau budi pekerti yang membedakan seseorang dengan yang lain. Oleh karena itu, karakter adalah nilai yang unik baik yang terpatri dalam diri dan terejawantahkan dalam perilaku.

Dalam pengertian sederhana pendidikan karakter adalah hal positif yang dilakukan guru dan berpengaruh kepada peserta didik yang diajarnya. Pendidikan karakter bukanlah pendidikan yang berbasis hafalan dan pengetahuan verbalistis, pendidikan karakter merupakan pendidikan perilaku yang terbentuk melalui habitual action dan pengejawatan keteladanan para pendidik, orang tua, para pemimpin, dan masyarakat yang merupakan lingkungan luas bagi pengembangan karakter anak.

\section{Nilai-nilai pendidikan karakter}

Dalam kajian kebudayaan, nilai merupakan inti dari setiap kebudayaan. Dalam konteks ini, khususnya nilai-nilai moral, merupakan sarana pengatur dari kehidupan bersama yang sangat menentukan sebuah budaya. Dalam nilai-nilai ini terdapat pembakuan tentang hal baik dan hal buruk serta pengaturan perilaku. Nilai-nilai hidup dalam masyarakat sangat banyak jumlahnya sehingga pendidikan berusaha membantu untuk mengenali, memilih dan menetapkan nilai-nilai tertentu sehingga dapat digunakan sebagai landasan pengambilan keputusan untuk berperilaku secara konsisten dan menjadi kebiasaan dalam hidup bermasyarakat.

Menurut Kementerian Pendidikan Nasional, Nilai karakter bangsa terdiri dari : Religius, jujur, toleransi, disiplin, kerja keras, kreatif, mandiri, demokratis, rasa ingin tahu, semangat kebangsaan, cinta tanah air, menghargai prestasi, bersahabat/komunikatif, cinta damai, gemar membaca, peduli lingkungan, peduli sosial dan tanggung jawab.

3. Hakikat pembelajaran ISMUBA (Islam, Muhammadiyah, Bahasa Arab)

Kawasan pendidikan Muhammadiyah, di antaranya terdiri dari keislaman, kebangsaan, keutuhan, kebersamaan dan keunggulan merupakan kesatuan integral yang patut dikembangkan di setiap lembaga pendidikan Muhammadiyah. Mengapa keislaman ditempatkan dalam urutan pertama? Sebab, sejauh ini salah satu ciri pendidikan Muhammadiyah yang paling menonjol adalah bidang agama Islam. Lewat dunia pendidikan, Muhammadiyah 
memasukkan "misi pencerahannya" kepada masyarakat umum. Dengan karakter demikian maka lembaga-lembaga pendidikan Muhammadiyah tidak ada yang tidak mengajarkan butir-butir pelajaran Al-Islam, ke-Muhammadiyahan dan Bahasa Arab (Ismuba).

Ketiga pelajaran ini merupakan tulangpunggung Persyarikatan dalam rangka menyampaikan dakwah Muhammadiyah. Kaderisasi Muhammadiyah secara inhern berada dalam mata pelajaran Ismuba tersebut. Dalam pelajaran ini terdapat muatan yang bersifat ideologis, seperti yang terkandung dalam ke-Muhammadiyahan misalnya. Pelajaran Ismuba yang diajarkan pada peserta didik dalam masa dini adalah satu hal yang sangat tepat. Sebab, melalui mata pelajaran tersebut para peserta didik dapat mengetahui Risalah Islam dan dinamika gerakan Muhammadiyah dalam panggung sejarah nasional.

\section{Penguatan pendidikan karakter} berbasis kearifan lokal

Penguatan dapat maknai sebagai suatu tindakan yang sengaja dilakukan untuk memperkuat sesuatu. Dalam Kamus Besar Bahasa Indonesia (KBBI), penguatan diartikan sebagai proses, cara, atau perbuatan untuk menguati atau menguatkan.

Dalam buku Desain Induk Pendidikan Karakter dijelaskan bahwa dalam rangka mengembangkan kegiatan intervensi, pengintegrasian pendidikan karakter dilakukan kedalam semua materi pembelajaran.

Substansi nilai sesungguhnya secara eksplisit atau implisit sudah ada dalam rumusan kompetensi baik dalam Kompetensi Inti (KI) maupun Kompetensi Dasar (KD) dalam satuan pendidikan dasar dan pendidikan menengah. Yang perlu dilakukan lebih lanjut adalah memastikan bahwa pembelajaran materi pembelajaran tersebut memiliki dampak instruksional dan/atau dampak pengiring pembentukan karakter.

Praktik pendidikan karakter pada satuan pendidikan formal dan nonformal bukan hanya menjadi tanggung jawab materi pelajaran Pendidikan Agama atau Pendidikan Kewarganegaraan (PKn). Inti dari Pendidikan Agama adalah pengembangan nilai iman,

takwa dan akhlak mulia. Adapun inti dari Pendidikan Kewarganegaraan (PKn) adalah pengembangan akhlak kewarganegaraan (civic virtue) yang mencakup kecerdasan kewarganegaraan (civic intelligennce), tanggungjawab kewarganegaraan (civic responsibility) dan partisipasi kewarganegaraan (civic participation). Selama ini terkesan materi pembelajaran lainnya hanya mengajarkan pengetahuan dari disiplin ilmu, teknologi, atau seni yang menaunginya. Oleh sebab itu, materi pembelajaran lain harus diperkuat dengan misi pendidikan karakter yang bersifat melekat dalam substansi dan proses keilmuan sebagai dimensi aksiologinya. Oleh karena itu, proses pembelajaran nilainilai karakter secara substantif diintegrasikan dalam setiap materi pembelajaran atau antar materi pembelajaran.

Pengembangan kualitas sumberdaya manusia, terutama di bidang pendidikan harus senantiasa menjadi prioritas pengembangan nasional maupun daerah. Dalam perkembangan konsepsi otonomi daerah, kewenangan pemerintah daerah dalam bidang pendidikan menjadi lebih luas, terutama pada sisi lain otonomi daerah di bidang pendidikan membawa konsekuensi tanggung jawab lebih besar bagi pemerintah daerah. 
Setidak-tidaknya terdapat tanggung jawab pemerintah daerah dalam hubungan dengan realisasi gagasan, kebijakan dan regulasi otonomi daerah di bidang pendidikan Di Kalimantan tengah sendiri terdapat Cagar budaya yang merupakan warisan budaya kearifan lokal masyarakat Kalimantan tengah pada umumnya, yaitu "Huma Betang”. Huma Betang adalah rumah adat masyarakat Kalimantan Tengah. Rumah yang dibangun dengan cara gotong royong ini berukuran besar dan panjang mencapai 30 - 150 meter , lebarnya antara 10-30 meter, bertiang tinggi antara 3-4 meter dari tanah. Penghuni Huma Betang bisa mencapai seratus bahkan dua ratus jiwa yang merupakan satu keluarga besar dan dipimpin oleh seorang Bakas lewu atau Kepala Suku. Huma Betang dibuat tinggi dengan maksud untuk menghindari dari banjir, serangan musuh, dan juga binatang buas. Lantai dan dindingnya terbuat dari kayu , sedangkan dibagian atap terbuat dari sirap. Kayu yang dipilih untuk membangun Huma Betang ini ialah kayu ulin selain anti rayap , kayu ulin mampu bertahan hingga ratusan tahun.

Individu yang menetap di Huma Betang sangat menjunjung tinggi prinsip 4 Pilar Huma Betang. Layaknya 4 Pilar bangsa Indonesia yang menjadi karakteristik individu yang tinggal di dalamnya, 4 Pilar karakteristik Huma Betang merupakan prinsip atau dasar pedoman dalam hidup bermasyarakat. Empat Pilar karakteristik tersebut sangat menjunjung

tinggi nilai persatuan, kepatuhan, dan toleransi. Berikut ulasan mengenai 4 Pilar karakteristik Huma Betang :
a. Kejujuran,
b. Kebersamaan,

c. Kerukunan, dan

d. Taat hukum dan agama

Kejujuran menciptakan kebenaran, kebenaran mendorong terciptanya kebersamaan, kebersamaan tumbuh menciptakan persatuan, persatuan tumbuh dengan penuh rasa toleransi dan kerukunan. Kerukunan menciptakan kemenangan dalam menghadapi perbedaan. Ketaatan dan kepatuhan memperkuat jiwa untuk terus melaju dalam jalan yang lurus.

Kejujuran, kebersamaan, kerukunan dan ketaatan yang dicerminkan oleh masyarakat suku Dayak menggambarkan karakteristik yang menjunjung tinggi semboyan "Bhineka Tunggal Ika" guna mencapai cita cita "Mamangun Tuntang Mahaga Lewu" demi menciptakan Indonesia yang sejahtera dan berkarakter.

\section{Hasil Penelitian dan Pembahasan}

Di dalam pembahasan ini menguraikan mengenai bagaimana Pendidikan dan nilai-nilai karakter berbasis kearifan lokal huma betang dalam kegiatan pembelajaran ISMUBA di SMA Muhammadiyah Kasongan

I. Pendidikan karakter berbasis kearifan lokal huma betang dalam kegiatan pembelajaran ISMUBA kelas $X$ IPS di SMA Muhammadiyah Kasongan

Terkait persiapan dari aspek perangkat pembelajaran, guru ISMUBA tersebut sudah melakukan persiapan dengan baik dari segi perangkat pembelajarannya.

Dalam hal lain mengenai pengetahuan terhadap teori tentang pendidikan karakter, Guru ISMUBA tersebut mengetahui urgensi dari nilai-nilai karakter seperti fungsi dan dampak positifnya, selain itu beliau juga mengaplikasikan langsung karakter yang 
beliau ketahui tersebut. Meskipun beliau tidak menyebutkan dan tidak hapal keseluruhan nilai-nilai karakter seperti yang ada di dalam teori, pengaplikasian langsung sikap dan prilaku yang diperlihatkan oleh DP selaku guru ISMUBA menjadi nilai lebih.

Adapun bentuk kegiatan dalam membimbing atau mengarahkan peserta didik untuk memiliki nilai karakter beragam, tidak hanya di dalam kelas, namun juga di luar kelas. Tidak hanya tugas guru ISMUBA, tapi tugas seluruh dewan guru yang ada di SMA Muhammadiyah Kasongan. Meskipun jawaban yang diberikan oleh subjek dan informan terkesan umum dan tidak spesifik, namun bisa kita lihat dalam observasi kegiatan pembelajaran, baik dalam kelas maupun di luar kelas seperti kegiatan kepramukaan, organisasi yang ada di sekolah dan lain-lain.

Kemudian strategi khusus untuk membentuk karakter yang berlandaskan huma betang adalah disamping dengan program pembiasaan yang dapat menunjang karakter filosofis huma betang (kejujuran, kebersamaan, kerukunan, serta taat hukum dan agama) juga dengan mengemas RPP dengan muatan-muatan nilai karakter yang diharapkan

Salah satu media yang digunakan dalam mengembangkan nilai karakter huma betang di sekolah SMA Muhammadiyah Kasongan adalah salah satunya lewat media "buku penghubung siswa”. Buku penghubung siswa ini berfungsi untuk mengontrol kegiatan keagamaan siswa terutama yang beragama islam. Lewat buku penghubung siswa ini dapat menjadi media pengajaran dalam mengembangkan nilai-nilai karakter filosofis huma betang.
Bentuk usaha dan fasilitas yang dilakukan dalam mendukung dan berkembangnya nilai-nilai krakter filosofi Huma betang di SMA Muhammadiyah kasongan sudah sangat mendukung dan fasilitas ini lagi-lagi tidak hanya mencakup di dalam kelas namun juga diluar kelas, artinya usaha dan fasilitas yang diberikan dan diusahakan ini bersifat umum atau dalam arti lain untuk seluruh siswa SMA Muhammadiyah pada umumnya, tidak dibatasi hanya kelas tertentu. Contohnya : dalam kelas ada yang disebut tata tertib kelas sebagai aturan bagi mereka untuk taat hukum yang telah dibuat bersama, hal ini akan menunjang kenyamanan kelas untuk menciptakan suasana belajar dan kebersamaan yang nyaman, mewujudkan toleransi dan kerukunan di kelas. Diluar kelas, nilai kejujuran sekolah menyediakan yang bernama tempat pengaduan temuan barang, kemudian nilai kebersamaan sekolah menciptakan suasana kelas dan lingkungan sekolah yang bisa dan mudah diakses dan nyaman untuk terjadinya interaksi, kemudian siswa diarahkan untuk mau berorganisasi dan mengikuti ekskul supaya menciptakan suasana kebersamaan sehingga saling bekerjasama antar siswa.

Selanjutnya, nilai kerukunan/toleransi sekolah memfasilitasi lewat perlakuan yang sama terhadap seluruh warga sekolah tanpa membedakan suku, ras, agama, status social dan ekonomi. Kemudian, untuk menunjang nilai taat hukum dan agama maka sekolah memberikan fasilitas seperti memiliki catatan kehadiran, walaupun dalam kelas adanya tata tertib kelas yang berisi imbauan-imbauan melalui kata-kata bijak di dinding-dinding kelas untuk taat aturan yang berkaitan dengan agama, adanya fasilitas tempat ibadah 
dan selalu merayakan hari-hari besar keagamaan.

2. Nilai dan Analisis Nilai Pendidikan Karakter Berbasis Kearifan Lokal Huma Betang dalam Kegiatan Pembelajaran ISMUBA Kelas X IPS di SMA Muhammadiyah Kasongan

Untuk mendapatkan hasil penelitian terhadap nilai dan analisis nilai pendidikan karakter huma betang ini dalam kegiatan pembelajaran ISMUBA kelas $X$ IPS di SMA Muhammadiyah ini dilakukan dengan wawancara langsung terhadap subjek dan informan serta didukung dengan data observasi dan dokumentasi. Hasilnya seperti yang diuraikan di bawah ini.

Guru ISMUBA di SMA Muhammadiyah punya metode tersendiri dalam mengintegrasikan nilai-nilai karakter ke dalam kegiatan pembelajarannya, seperti yang disampaikan oleh guru ISMUBA. Bahkan upaya-upaya teknis yang dilakukan dalam penanaman nilai-nilai karakter diserahkan sepenuhnya kepada guru. Dalam hal ini DP selaku guru ISMUBA di sekolah SMA Muhammadiyah melakukannya dengan cara pembiasaan dalam kegiatan pembelajarannya, seperti berdo'a setiap memulai pelajaran untuk menumbuhkan nilai-nilai karakter religius, taat hukum dan Agama.

Kemudian Guru ISMUBA membagi dua proses pembelajaran, yaitu di dalam kelas dan di luar kelas. Adapun di dalam kelas terkait proses pembelajaran, sedangkan di luar kelas terkait aspek sikap perilaku siswa, kebiasaan dan kegitan siswa seperti ekskul dan organisaasi yang ada di sekolah. Dari kedua kesempatan itulah menjadi kesempatan besar untuk menanamkan nilainilai karakter, khususnya nilai-nilai karakter kearifan lokal huma betang. Hal ini menggambarkan luasnya ranah pendidikan karakter di lingkup sekolah.

Kegiatan pembiasaan dalam penanaman nilai karakter kearifan lokal di SMA Muhammadiyah Kasongan beragam, bisa di dalam kelas maupun di luar kelas, seperti yang dijelaskan sebelumnya, dimana guru ISMUBA memberikan contoh kegiatan pembiasaan di dalam kelas (kegiatan pembelajaran) dan di luar kelas (di luar kegiatan pembelajaran). Misalnya: lewat pembiasaan sholat berjamaah di masjid sekolah, menyediakan fasilitas temuan barang, menciptakan suasana sekolah dan lingkungan yang nyaman dan mudah diakses, mengembangkan ekskul dan organisasi, hal ini baik menunjang nilai karakter filosofis huma betang yang sarat makna akan nilai kejujuran, kebersamaan, kerukunan serta taat hukum dan agama. Dari contoh-contoh yang disebutkan tadi adalah sebagian kecil dari banyak sekali kegiatan pembiasaan yang dilakukan di sekolah tersebut.

Adapun penilaian dari setiap pembelajaran, DP selaku guru ISMUBA menilainya yaitu melalalui 3 sisi : pengetahuan, keterampilan dan sikap. DP menjelaskan bahwa dalam pendidikan karakter bisa di nilai melalui penilaian sikap. Adapun indikator penilain sikap dapat dilihat melalai buku bobot poin siswa dan pengaplikasian niali-nilai karakter dalam sehari-hari terutama di lingkungan sekolah mulai dari mentaati tata tertib kelas dan sekolah sampai dengan berperilaku baik dan sopan. Ketika sudah menjadi suatu kebiasaan di lingkungan sekolah, hal ini dapat terbawa di lingkungan lainnya seperti ranah keluarga dan masyarakat.

a. Muatan Nilai Pendidikan Karakter Berbasis Kearifan Lokal Huma 


\begin{abstract}
Betang dalam Kegiatan Pembelajaran ISMUBA Kelas X IPS di SMA Muhammadiyah Kasongan Pendidikan karakter berbasis kearifan lokal huma betang dalam kegiatan pembelajaran ISMUBA kelas $X$ IPS di SMA Muhammadiyah Kasongan berjalan baik dengan perencanaan kegiatan pembelajaran yang baik dan terencana pula. Hal ini dapat terlihat dari nilai-nilai karakter yang muncul di setiap pembelajarannya. Dengan mengusung visi dan misi penguatan karakter, maka nilai-nilai karakter yang lebih ditekankan dalam kegitan pembelajarannya, baik itu kegiatan pembelajaran di dalam kelas maupun kegiatan pembelajaran di luar kelas.
\end{abstract}

Nilai karakter dalam kegiatan pembelajaran ISMUBA di SMA Muhammadiyah sangatlah luas, tidak hanya mencakup nilai-nilai karakter huma betang, artinya nilai-nilai filosofi karakter huma betang yang memiliki nilai kejujuran, kebersamaan, kerukunan/toleransi serta taat hukum dan agama ini merupakan bagian dari nilai-nilai karakter yang ditanamkan oleh sekolah pada umumnya dan oleh guru ISMUBA pada khususnya.

Adapun nilai karakter yang
muncul lewat pendidikan karakter
berbasis kearifan lokal huma betang
dalam kegiatan pembelajaran ISMUBA
kelas X IPS di SMA Muhammadiyah
Kasongan yaitu:
a. Disiplin,
b. Religius,
c. Toleransi,
d. Peduli sosial,
e. Rasa ingin tahu,

f. Gemar membaca,

g. Kerja keras,

h. Tanggung jawab,

i. Kreatif,

j. Jujur,

k. Bersahabat/komunikatif,

I. Menghargai prestasi.

$\mathrm{m}$.

b. Tugas dan Peran Guru ISMUBA dalam Penanaman Nilai Karakter Kearifan Lokal Huma Betang dalam Kegiatan Pembelajaran ISMUBA Kelas $X$ IPS di SMA Muhammadiyah Kasongan

I) Tugas guru ISMUBA dalam penanaman karakter kearifan lokal .huma betang

Tugas guru dalam penanaman nilai karakter pada peserta didik kelas $X$ IPS di SMA Muhammadiyah Kasongan sudah terjalin dengan baik. Hal tersebut dapat dilihat dari aktivitas kegiatan pembelajaran di dalam dan di luar kelas yang sudah memuat nilai-nilai karakter. Adapun tugas guru dalam hal ini yaitu memposisikan diri sebagai pengajar, pendidik dan sebagai pelatih.

2) Peran guru ISMUBA dalam penanaman karakter kearifan lokal huma betang

Pada penelitian ini guru kurang memenuhi komponen kriteria peran guru dalam penanaman nilai karakter, khususnya karakter huma betang pada kegiatan pembelajaran, dari 9 (sembilan) peran yang semestinya harus dijalankan. pada kenyataannya guru hanya menjalankan 6 (enam) peran saja, yaitu: 

a. Sebagai Motivator,
b. Sebagai pengarah/director,
c. Sebagai inisiator,
d. Sebagai Mediator,
e. Sebagai Fasilitator,
f. Sebagai Evaluator.

\section{Kesimpulan}

Berdasarkan penelitian di atas dapat disimpulkan bahwa :

I. Pendidikan karakter berbasis kearifan lokal huma betang dalam kegiatan pembelajaran ISMUBA kelas X IPS di SMA Muhammadiyah Kasongan berjalan baik dengan perencanaan kegiatan pembelajaran yang baik dan terencana pula. Hal ini dapat terlihat dari nilai-nilai karakter yang muncul di setiap pembelajarannya. Dengan mengusung visi dan misi penguatan karakter, maka nilai-nilai karakter yang lebih ditekankan dalam kegitan pembelajarannya, baik itu kegiatan pembelajaran di dalam kelas maupun kegiatan pembelajaran di luar kelas seperti ekstrakurikuler, organisasi dan kegiatan keagamaan.

Nilai karakter kearifan lokal huma betang dalam kegiatan pembelajaran ISMUBA kelas $X$ IPS di SMA Muhammadiyah Kasongan tercermin dari sikap dan perilaku yang muncul di dalam kegiatan pembelajaran maupun di luar pembelajaran seperti berikut

a. Nilai kejujuran

I) Mengerjakan soal latihan dengan jujur tanpa menyontek,

2) Bertanya ketika tidak mengerti tentang materi yang sudah disampaikan,

3) Menyerahkan barang temuan kepada petugas penjaga tempat temuan barang, dll. b. Nilai Kebersamaan

I) Mengerjakan tugas kelompok,

2) Diskusi Kelas,

3) Aktif di dalam organisasi-organisasi yang dibuat oleh sekolah seperti IMM,

4) Aktif dalam ekstrakurikuler yang ada di sekolah seperti Pramuka, Drum Band, Tapak Suci untuk mengasah kemampuan, menanamkan nilai kebersamaan dan kerjasama antar siswa.

c. Nilai kerukunan/toleransi

I) Menjaga suasana kelas tetap kondusif,

2) Saling Menghormati antar sesama siswa tanpa membedakan suku, ras, agama, maupun status sosial, dll.

d. Nilai taat hukum dan agama

I) Mematuhi tata tertib kelas dan tata tertib sekolah,

2) Menjalankan perintah agama, seperti menjalankan ibadah sholat berjamaah bagi yang beragama muslim.

2. Nilai karakter yang muncul dari Pendidikan karakter berbasis kearifan lokal huma betang dalam kegiatan pembelajaran ISMUBA kelas $X$ IPS di SMA Muhammadiyah Kasongan ini adalah nilai karakter disiplin, religius, toleransi, peduli sosial, rasa ingin tahu, gemar membaca, kerja keras, tanggung jawab, kreatif, jujur, bersahabat/komunikatif dan menghargai prestasi.

Dalam penanaman nilai karakter huma betang terhadap peserta didik kelas $X$ IPS di SMA Muhammadiyah guru ISMUBA memiliki tugas dan peran sebagai berikut

a. Tugas guru ISMUBA kelas X IPS di SMA Muhammadiyah dalam penanaman nilai 
karakter filosofi huma betang adalah sebagai pendidik, pengajar dan pelatih,

b. Peran guru ISMUBA dalam penanaman nilai karakter huma betang terhadap peserta didik kelas $X$ IPS di SMA Muhammadiyah yaitu sebagai motivator, pengarah/director, inisiator, mediator, fasilitator dan evaluator.

\section{DAFTAR PUSTAKA}

Ghony dan Aimansyur, 2016, Metodologi penelitian kualitatif, Yogyakarta : Ar-Ruzz Media

Kesuma Dharma, Cepi Triatna, Johar Permana, 2012, Pendidikan Karakter Kajian Teori dan Praktik di Sekolah. Bandung: PT. Remaja Rosdakarya

Koesoema Dhoni, 2007, Pendidikan Karakter Strategi Mendidik Anak di Zaman Global, Jakarta: PT Gramedia Widiasarana Indonesia

Muslich Masnur, 20I I, pendidikan karakter menjawab tantangan krisis multidimensional, Jakarta : Bumi Aksara

Ramayulis, Ilmu Pendidikan Islam, Jakarta: Kalam Mulia, 2008

Salahudin Anas, 2013, Pendidikan Karakter (pendidikan Berbasis agama dan budaya bangsa), Bandung: CV Pustaka Setia
Sardiman, 2014, Interaksi dan Motivasi belajar mengajar, Jakarta : PT Raja Grafindo Persada

Samani Muchlas dan Hariyanto, 2012, Konsep dan Model Pendidikan Karakter. Bandung: PT. Remaja Rosdakarya

Sugiyono, 2015, Metode Penelitian Tindakan Komprehensif (Untuk Perbaikan Kinerja dan Pengembangan Ilmu Tindakan). Bandung: Alfabeta.

Sugiyono, 2016, Metode Penelitian Tindakan Komprehensif (Untuk Perbaikan Kinerja dan Pengembangan Ilmu Tindakan). Bandung: Alfabeta

Sugiyono, 2019, Metode Penelitian Kuantitatif, Kualitatif dan R\&D, Bandung : Alfabeta, Cet. Ke-6

Supriadi Gito, 2015 Modul mata kuliah metodologi penelitian pendidikan, Palangkaraya : Cetakan Pribadi

Pustaka Online :

https://aguswuryanto.wordpress.com/2012/02/23/cont oh-indikator-keberhasilan-pelaksanaanpendidikan-karakter-di-sekolah/

https://drive.google.com/drive/folders/0Bxf5GRcs7wu IcE9CYndnaDNOZWM

https://penilaianpembelajaran.blogspot.com/2014/03/p enilaian-sikap.html 